\title{
MARLI ANDRÉ - O LEGADO DE UMA MULHER INTELECTUAL DO NOSSO TEMPO E ESPAÇO
}

\author{
Eurize PESSANHA \\ Universidade Federal da Grande Dourados - UFGD \\ Dourados, Mato Grosso do Sul - Brasil \\ eurizep@uol.com.br \\ ORCID.https.orcid.org//0000-0002-1564-3362
}

\begin{abstract}
RESUMO: Este texto buscou evidenciar o legado da mulher intelectual Marli André nas palavras com que teceu os textos em que disseminou suas ideias e influenciou muitos pesquisadores das áreas de Didática, Prática e Formação de Professores, Pesquisa Qualitativa. Foram analisados os títulos dos 111 artigos publicados em periódicos registrado no Currículo Lattes da pesquisadora para verificar como os títulos de suas publicações e os veículos em que publicou enunciam a trajetória desta pesquisadora. Conclui-se que Marli André é uma mulher intelectual da educação cujo legado vai além dos seus escritos pois os grupos de pesquisa que criou e dos quais participou, seus alunos e orientandos continuam gerando produção intelectual e formando novos pesquisadores e professores consolidando tal legado. Enuncia-se a proposta de dar continuidade a este trabalho de analisar a trajetória da produção do conhecimento da mulher intelectual da educação do nosso espaço e do nosso tempo.
\end{abstract}

PALAVRAS-CHAVE: Marli André. Pesquisa Educacional. Intelectuais. Formação de professores

\section{MARLI ANDRÉ - THE LEGACY OF AN INTELLECTUAL WOMAN OF OUR TIME AND SPACE}

ABSTRACT: This text sought to highlight the legacy of the intellectual woman Marli Andre based on the texts in which she disseminated her ideas and influenced many researchers in the areas of Didactics, Practice and Teacher Training, Qualitative Research. The titles of 111 articles published in journals registered in the researcher's Curriculum Lattes were analyzed to verify how the titles of the publications and the vehicles in which she published enunciate the trajectory of the researcher. It is concluded that Marli André is an intellectual woman of education whose legacy goes beyond her writings because the research groups she created and in which she participated, her students and supervisees, continue to generate intellectual production and train new researchers and teachers, consolidating this legacy. The proposal is set out to continue this work of analyzing the trajectory of knowledge production of intellectual women in education in our space and time.

KEYWORDS: Marli André. Educational Research. Intellectuals. Teacher training 


\section{MARLI ANDRÉ - EL LEGADO DE UNA MUJER INTELECTUAL DE NUESTRO TIEMPO Y ESPACIO}

RESUMEN: Este texto buscó resaltar el legado de la mujer intelectual Marli André en las palabras con las que tejió los textos en los que difundió sus ideas e influyó en muchos investigadores en las áreas de Didáctica, Práctica y Formación Docente, Investigación Cualitativa. Se analizaron los títulos de 111 artículos publicados en revistas inscritas en el Curriculum Lattes de la investigadora para verificar cómo los títulos de sus publicaciones y los vehículos en los que publicaron enuncian la trayectoria de esta investigadora. Se concluye que Marli André es una mujer intelectual de la educación cuyo legado va más allá de sus escritos porque los grupos de investigación que creó y en los que participó, sus alumnos y supervisados, continúan generando producción intelectual y formando nuevos investigadores y docentes, consolidando este legado. . Se propone continuar con este trabajo de análisis de la trayectoria de la producción de conocimiento de las mujeres intelectuales en la educación en nuestro espacio y tiempo.

PALABRAS-CLAVE: Marli André. Investigación Educativa. Intelectuales. Formación de profesores 


\section{Introdução}

Quando comecei a planejar a escrita deste artigo para compor um dossiê sobre as contribuições de Marli Elisa Dalmazo Afonso de André para a pesquisa em educação e para o campo da formação de professores, lembrei-me de que, em 2006, Marli escreveu na Revista Diálogo Educacional um artigo com o título A jovem pesquisa educacional brasileira (ANDRÉ, 2006). Hoje, 25 anos depois, pode-se dizer que a pesquisa educacional brasileira continua jovem, na definição de Houaiss: que ainda não alcançou seu pleno desenvolvimento (2009, p. 1135), mas indicando também que continua com o vigor da juventude, como se pode constatar pela constante inclusão de temáticas, referenciais, abordagens, produções e pesquisadores ${ }^{1}$. Nesse artigo, Marli André aborda e analisa a trajetória da pesquisa educacional no Brasil, iniciada com a criação do INEP Instituto Nacional de Estudos Pedagógicos, nos anos 30 do século XX, descrevendo as fases que, segundo a autora, foram marcos dessa trajetória: Os anos iniciais - nascimento induzido (1938 a 1970); A institucionalização da Pesquisa Educacional - a maioridade quase forçada (década de 1970); O crescimento da Pesquisa Educacional - rumo à maturidade? (últimos 20 anos).

Cotejando a trajetória da pesquisadora Marli André com a história da jovem pesquisa educacional, foi ficando claro que ela participou diretamente de todas essas fases, com exceção apenas dos "anos iniciais", embora a experiência no ginásio Estadual Pluricurricular Experimental GEPE I que, segundo o que escreveu em seu

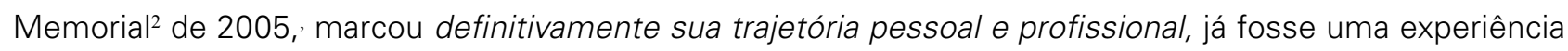
de iniciação à pesquisa porque provocou a busca por cursos de pós-graduação, inicialmente na modalidade especialização e, depois, por curso de pós-graduação stricto sensu ingressando, em 1974, no Mestrado em Educação da PUC-Rio, quando fomos contemporâneas e iniciamos uma convivência sobre cujas lembranças discorri em texto em sua homenagem (PESSANHA, 2021). Sua formação se completou com o Doutorado em Educação realizado na Universty of llinois na cidade de Urbana-Champaign que concluiu em 1978. Desde então, a história da Pesquisa Educacional, no Brasil, notadamente sobre formação e práticas de professores, foi marcada pela atuação de Marli André.

Como já pontuei no texto mencionado, algumas "coincidências" nos aproximaram: idades próximas, tanto de nascimento quanto de formação, mesmos cursos de graduação e mesma época de conclusão do mestrado em Educação na PUC-Rio. Depois, por escolha e não mais coincidência, investiguei a trajetória histórica do professor primário no Brasil (PESSANHA, 1992) sob sua segura, instigante e estimulante orientação no Doutorado na Faculdade de Educação da USP.

Como pesquisadora venho, há algumas décadas, investigando e produzindo no Campo da História da Educação e é deste lugar que, ao planejar a escrita deste texto, vislumbrei a possibilidade de destacar, em sua produção bibliográfica as marcas e a trajetória de sua participação destacada, significativa e marcante em todas as etapas da história da pesquisa educacional e da produção do conhecimento sobre a educação no Brasil, notadamente sobre formação e práticas de professores.

Foram tantas as palavras, seu instrumento de trabalho, que Marli pronunciou e escreveu como pesquisadora, que por sermos ambas "das letras" por formação, torna-se irresistível trazer para este diálogo, Cecília Meireles com:

1 Tomo como exemplo a recente aprovação pela Assembleia da ANPED, de um novo GED, justificado pelo aprofundamento e ampliação alcançados pelos estudos sobre cotidiano.

2 Como parte do processo para ingressar no Programa de Pós-graduação de Psicologia da PUC/SP, em 2005, Marli André escreveu um Memorial que estava entre documentos/pastas por ela guardados e foram liberados pelos seus filhos. Com ajuda de Laurizete Ferragut Passos, tive acesso a esse documento, doravante denominado Memorial, uma das fontes deste artigo. 


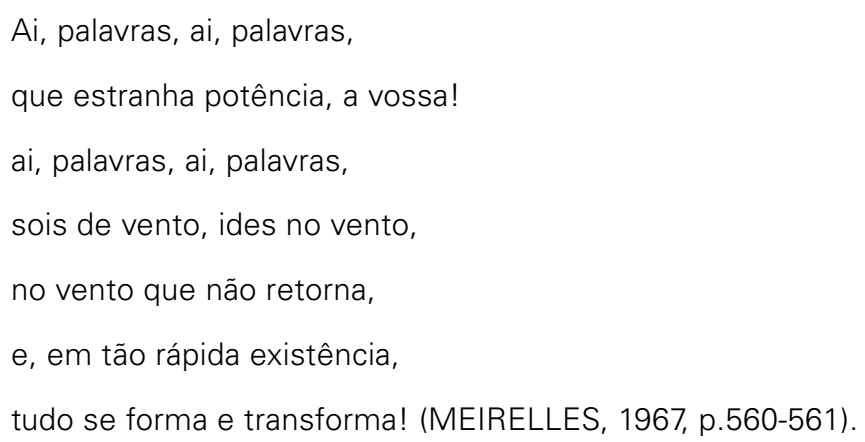

A lembrança de Cecília vem associada à de Carlos Drummond de Andrade ao nos alertar que há um reino das palavras no qual se penetra surdamente

\section{[...] Chega mais perto e contempla as palavras. Cada uma}

tem mil faces secretas sob a face neutra

e te pergunta, sem interesse pela resposta, pobre ou terrível, que lhe deres:

Trouxeste a chave? (ANDRADE, 1979, P. 161

Com essa introdução com base na Literatura, felizmente não mais tão rara nos escritos acadêmicos, anuncio o propósito deste texto: evidenciar o legado da mulher intelectual Marli André nas palavras com que teceu os textos em que disseminou suas ideias e influenciou muitos pesquisadores das áreas de Didática, Prática e Formação de Professores, Pesquisa Qualitativa.

\section{Desenvolvimento}

Para começar, faço como Certeau, para quem, em história, tudo começa com o gesto de separar e reunir, transformando-os em documentos, determinados objetos antes dispostos de outra maneira. (CERTEAU, 2002, P. 81). Aqui, esses objetos mencionados por Certeau estão dispostos no Currículo Lattes de Marli3: 111 artigos publicados em 64 periódicos diferentes, 12 Livros publicados, 108 capítulos de livros e 95 trabalhos completos publicados em anais de eventos nacionais e internacionais.

Para separar e reunir, a primeira tarefa foi localizar os textos completos dos 111 artigos. Embora facilitada pelos mecanismos de busca da internet, essa busca ainda não está completa: 30 dos artigos listados não foram encontrados. Mesmo assim, o acesso a mais de 70\% dos artigos completos forneceu informações suficientes para responder a algumas questões iniciais: Como os títulos de suas publicações e os veículos em que publicou enunciam a trajetória desta pesquisadora? Que conceitos, temáticas, referências, relações, cruzamentos e ausências são evidenciados?

Os primeiros artigos de Marli André foram publicados no final da década de 1970: em 1978, publicou A Abordagem Etnográfica: Uma Nova Perspectiva na Avaliação Educacional, na revista Tecnologia Educacional, e O Que Dizem As Pesquisas Na Salas de Aula do Primeiro Grau? na revista Forum Educacional. No ano seguinte, em coautoria com seu orientador de doutorado, publicou The Development And Evaluation Of $A$ 
Self Questioning Study Tecnique, na revista Reading Research Quaterly, e Um Estudo da Interação Professor Aluno Na Segunda Série do Primeiro Grau, na revista Cadernos de Pesquisa da Fundação Carlos Chagas.

Nos títulos desses quatro primeiros trabalhos, já se vislumbram as temáticas que vão ser constantes na sua trajetória e sobre as quais exerceu grande influência nas pesquisas da área: estudos etnográficos, pesquisa em sala de aula e professor, tema que aparece em praticamente a metade de todos os artigos.

Convém ressaltar que, dos 111 artigos publicados, nada menos que 60 foram elaborados em coautoria, tendência que se acentuou nos últimos anos de sua produção pois, dos 46 artigos publicados de 2010 a 2020, 33 são em coautoria, consoante com a percepção de que, para Marli, pesquisar é uma tarefa coletiva.

O propósito, enunciado nos primeiros parágrafos deste texto, de destacar em sua produção bibliográfica as marcas e a trajetória de sua participação destacada, significativa e marcante em todas as etapas da história da pesquisa educacional e da produção do conhecimento sobre a educação no Brasil, notadamente sobre formação e práticas de professores, ainda é uma tarefa em progresso, por isso, apresento apenas alguns resultados parciais, baseado na leitura dos títulos dos 111 artigos registrados no CV Lattes e, quando disponíveis, nas palavras-chave ou resumos. (QUADRO 1)

\section{Quadro 1 - Temáticas abordadas nos títulos dos 111 artigos publicados por Marli André registrados em seu currículo lattes até 2020.}

\begin{tabular}{|c|c|c|c|c|c|c|}
\hline \multicolumn{2}{|c|}{ TEMÁTICAS/PERÍODOS } & \multirow{2}{*}{$\begin{array}{l}\text { DÉCADA } \\
\text { DE } 1970\end{array}$} & \multirow{2}{*}{$\begin{array}{l}\text { DÉCADA } \\
\text { DE } 1980\end{array}$} & \multirow{2}{*}{$\begin{array}{l}\text { DÉCADA } \\
\text { DE } 1990\end{array}$} & \multirow{2}{*}{$\begin{array}{l}\text { DÉCADA } \\
\text { DE } 2000\end{array}$} & \multirow{2}{*}{$\begin{array}{l}\text { DÉCADA } \\
\text { DE } 2010\end{array}$} \\
\hline TEMÁTICAS & SUBTEMAS & & & & & \\
\hline \multirow{10}{*}{$\begin{array}{l}\text { FORMAÇÃO E } \\
\text { PRÁTICAS DE } \\
\text { PROFESSORES }\end{array}$} & $\begin{array}{l}\text { PROFESSOR/DOCENTE/ } \\
\text { DOCÊNCIA }\end{array}$ & $x$ & $x$ & $x$ & $x$ & $x$ \\
\hline & DIDÁTICA & & $x$ & $x$ & $x$ & $x$ \\
\hline & PRÁTICAS PEDAGÓGICAS & & $x$ & $x$ & $x$ & \\
\hline & $\begin{array}{l}\text { FORMAÇÃO DE } \\
\text { PROFESSORES }\end{array}$ & & & $x$ & $x$ & $x$ \\
\hline & $\begin{array}{l}\text { PROFISSIONALIDADE/ } \\
\text { IDENTIDADE DOCENTE }\end{array}$ & & & & $x$ & $x$ \\
\hline & TRABALHO DOCENTE & & & & $x$ & \\
\hline & $\begin{array}{l}\text { POLÍTICAS DE } \\
\text { FORMAÇÃO DE } \\
\text { PROFESSORES }\end{array}$ & & & & $x$ & $x$ \\
\hline & $\begin{array}{l}\text { PRODUÇÃO DE } \\
\text { CONHECIMENTO } \\
\text { DIDÁTICO }\end{array}$ & & & & & $x$ \\
\hline & $\begin{array}{l}\text { RELAÇÃO PESQUISA } \\
\text { FORMAÇÃO DE } \\
\text { PROFESSORES }\end{array}$ & & & & $x$ & \\
\hline & $\begin{array}{l}\text { RELAÇÃO PESOUISA E } \\
\text { DOCÊNCIA }\end{array}$ & & & & $x$ & \\
\hline
\end{tabular}




\begin{tabular}{|c|c|c|c|c|c|c|}
\hline \multirow{8}{*}{$\begin{array}{l}\text { QUESTÕES } \\
\text { TEÓRICO } \\
\text { METODOLÓGICAS } \\
\text { DA PESQUISA EM } \\
\text { EDUCAÇÃO }\end{array}$} & $\begin{array}{l}\text { ESTUDOS } \\
\text { ETNOGRÁFICOS }\end{array}$ & $\mathrm{x}$ & & & & \\
\hline & ESTUDO DE CASO & & $x$ & & $x$ & $x$ \\
\hline & $\begin{array}{l}\text { PESQUISA EM SALA } \\
\text { DE AULA /COTIDIANO } \\
\text { ESCOLAR }\end{array}$ & $x$ & $\mathrm{x}$ & $\mathrm{x}$ & & \\
\hline & PESQUISA & & & $x$ & & \\
\hline & PESQUISA QUALITATIVA & & & $x$ & & \\
\hline & $\begin{array}{l}\text { PESOUISA/PRODUÇÃO } \\
\text { DE CONHECIMENTO }\end{array}$ & & & & $\mathrm{x}$ & \\
\hline & $\begin{array}{l}\text { CONDIÇÕES DE } \\
\text { PRODUÇÃO DE } \\
\text { CONHECIMENTO }\end{array}$ & & & & $x$ & \\
\hline & GRUPOS DE PESOUISA & & & & $x$ & \\
\hline \multirow[t]{2}{*}{ PÓS-GRADUAÇÃO } & $\begin{array}{l}\text { AVALIAÇÃO } \\
\text { PROGRAMAS DE } \\
\text { PÓS-GRADUAÇÃ̃O }\end{array}$ & & & & $x$ & \\
\hline & $\begin{array}{l}\text { MESTRADO } \\
\text { PROFISSIONAL }\end{array}$ & & & & $\mathrm{x}$ & $\mathrm{x}$ \\
\hline
\end{tabular}

Quadro elaborado pela autora. Fonte CV Lattes Marli André - 2020

Não há dúvida de que produção de Marli André foi marcada pela temática Professor, presente nos artigos do final da década de 1970 e em todas as décadas posteriores. durante toda a sua trajetória. A leitura dos títulos com essa temática induz a agregá-los sob uma categoria mais ampla: FORMAÇÃO E PRÁTICAS DE PROFESSORES. Os subtemas Professor, Didática e Práticas pedagógicas surgem na década de 1980 e se mantêm até a década de 2000, enquanto Formação de professores vai ser constante até 2020.

A partir de 2000, percebe-se uma inflexão para outros subtemas tais como Profissionalidade/identidade docente, Trabalho docente, Produção de conhecimento Didático, Relação pesquisa e docência; Relação Pesquisa e formação de professores e Políticas de Formação de Professores. Essa inflexão parece indicar tanto um aprofundamento quanto uma ampliação das temáticas iniciais dessa trajetória para responder a questões emergentes.

Analisar a trajetória da constituição do legado de Marli André, tendo como base sua produção em artigos publicados em periódicos, provoca a necessidade de voltar à sua formação. Em vez de me limitar às informações do CV Lattes, busquei o que ela escreveu no Memorial.

Ao mencionar sua formação no curso de Mestrado em Educação da PUC-Rio, merece destaque sua percepção de que naquele momento, as reflexões sobre ensino eram dominadas pelo tecnicismo e na pesquisa valorizava-se o modelo experimental (MEMORIAL...). acompanhando a proposta do programa para quebrar o domínio daquele tecnicismo, cursou disciplinas que focalizavam estudos sobre a realidade brasileira. Como consequência, inseriu-se em um grupo de pesquisa orientado por Menga Lüdke, quando aprendeu os passos de uma pesquisa, mas também marcou sua inserção nos estudos no interior da escola, 
O doutorado, realizado nos Estados Unidos, trouxe, ainda segundo seu Memorial, outro elemento que marcou sua trajetória de pesquisadora. Seguindo a recomendação do orientador, cursou todas as disciplinas de estatística desde a mais simples à mais sofisticada [preparou-se..]. muito bem na área quantitativa e me deu segurança para defender a abordagem qualitativa. (MEMORIAL...).

Em síntese, foi possível perceber que sua formação na pós-graduação stricto sensu deixou marcas registradas em sua produção, tais como: estudos no interior da escola, preocupação com a realidade brasileira, trabalho coletivo e abordagens qualitativas na pesquisa em educação.

Dada a importância da temática Formação de Professores e Práticas de Professores na produção de Marli André em artigos de periódicos e a repercussão de suas conclusões na pesquisa educacional, serão destacados alguns achado e considerações que constituem parte do legado para a área, privilegiando as publicações dos últimos 20 anos.

Em artigo publicado em 2000, como resultado da análise de dissertações e teses sobre Formação de professores defendidas em dois programas de pós-graduação da cidade de São Paulo, nos anos de 1998 e 1999, registrou que: identidade e competência docente, formação do profissional reflexivo/pesquisador, trabalho coletivo e mudanças de atitude foram os temas centrais dos trabalhos analisados e pesquisa-ação foi a metodologia pesquisa-ação, sendo que livros foram as fontes de consulta mais frequentes, enquanto artigos e dissertações/teses pouco aparecem (ANDRÉ, 2000, p. 151).

Em 2009, Marli publica texto cujo objetivo foi mostrar o potencial dos estudos de caso para revelar mudanças em contextos escolares e em concepções e práticas de professores que participaram do PROFORMAÇÃO Programa de Formação de Professores em Exercício. Os resultados de pesquisa que incluiu visitas às salas de aula dos cursistas, entrevistas, análises de memoriais e aplicação de testes de desempenho, mostraram mudanças em concepções e práticas pedagógicas dos professores, melhoria em suas habilidades de escrita e em sua auto estima, valorização da cultura local e das experiências dos alunos. (ANDRÉ, 2009, p. 139)

Ainda em 2009, artigo publicado na revista Educação traz como conclusão que o exame das relações entre as políticas e as pesquisas mostram que o Estado Avaliador tem privilegiado as pesquisas que se baseiam em dados quantitativos, criando novos tipos de regulação e aumentando as tentativas de controle dos atores do sistema. (ANDRÉ, 2009, p. 270)

Em 2013, a partir de dados coletados em secretarias de educação de estados e municípios, Marli identifica que, na maioria houve ações formativas dirigidas a um professor genérico, sem um acompanhamento dos efeitos dessas ações na escola e na sala de aula, além de não envolverem os docentes na definição dessas ações. (ANDRÉ, 2013, p. 48)

Baseadas em resultados de pesquisa, que incluiu grupos de discussão, entrevistas e observação em sala de aula, para conhecer quem é esse professor que ensina Didática, captar suas visões sobre Didática e identificar suas práticas em sala de aula para compreender como as concepções e práticas defendidas fundamentam o aprendizado da docência, Giseli Barreto da Cruz e Marli André concluíram que há uma tendência de ensinar Didática a partir do tratamento de temas necessários à formação de professores, sem, no entanto, se manifestar a preocupação com a afirmação da Didática fundamental, caracterizada pela multidimensionalidade do processo de ensinar e aprender (CRUZ, ANDRÉ, 2014, p. 181). Dada a importância da conclusão das autoras para as pesquisas e a prática da formação docente, cabe transcrever parte de suas conclusões, 


\begin{abstract}
Assumimos e defendemos a perspectiva de que o objeto da Didática diz respeito ao processo de compreensão, problematização e proposição acerca do ensino, sendo este entendido como o processo de fazer aprender alguma coisa a alguém, marcado pela mediação e pela dupla transitividade. (...) Dessa forma, o processo de ensinar incorpora em si mesmo o processo de aprender, constituindo-se como um único processo com movimentos distintos (ensinagem e aprendizagem), porém indissociáveis. [...] Saber ensinar é ser especialista da complexa capacidade de transformar o saber curricular mediado por um saber científico, por um domínio técnico-didático rigoroso, por uma postura meta-analítica, de questionamento intelectual da ação, de interpretação permanente e realimentação contínua, para que o aluno aprenda de forma contextualizada e com significado. (p. 201)
\end{abstract}

Voltando-se mais uma vez para as políticas de valorização do trabalho docente, Marli conclui que incentivos aos professores tendem a compensar o professor individualmente e que não há informações suficientes, de levantamentos ou de pesquisas, que possam atestar os efeitos dessas medidas na qualidade do ensino de sala de aula e na aprendizagem dos alunos. (ANDRÉ, 2015, P. 2013)

Para completar suas contribuições para os estudos e práticas da formação de professores, em artigo publicado em 2020, Cecília Rosa Lacerda e Marli André discutem as contribuições do Mestrado Profissional, ainda recente na Pós-graduação em Educação, para a formação do professor de Educação Básica, concluindo que o mestrado profissional, em um contexto desafiador, exprime-se como importante dispositivo para a melhoria da formação e aprendizagem docente. (LACERDA; ANDRÉ, 2020, p. 45)

Paralelamente, desde os primeiros artigos publicados, apontam reflexões sobre as questões teórico-metodológicas da Pesquisa em Educação, especificamente sobre Etnografia, Pesquisas sobre cotidiano da sala de aula, Estudos de caso, Pesquisa qualitativa, Pesquisa e Condições da produção de conhecimento e Grupos de Pesquisa.

Como consequência de sua participação nos Programas de Pós-graduação, nas Comissões de Avaliação da CAPES e nos Comitês do CNPq, a temática Pós-graduação começa a aparecer nos artigos a partir da década de 2000, tendo como subtemas Avaliação dos Programas de Pós-graduação e Mestrado Profissional.

Este artigo fica devendo a articulação dessa trajetória com a produção da área de Educação, mas, pode-se supor fortemente que os trabalhos de Marli foram indutores da expansão da produção de conhecimento nessas Temáticas e Subtemas na Pesquisa Educacional no Brasil.

Em relação às investigações sobre Formação de Professores, a própria pesquisadora, em artigo publicado em 2010 (ANDRÉ, 2010), formula e responde à questão: Pode-se dizer que a formação de professores constitui um campo autônomo de estudos? (p. 174) concluindo que,

Com base em cinco critérios propostos por Garcia (1999) [e]: Apoiado em pesquisas da área, assim como em várias iniciativas da comunidade científica, o texto conclui que houve muitos avanços, nos últimos dez anos, no sentido da constituição de um campo autônomo de estudos e aponta alguns caminhos para fortalecer a área (p. 173)

A participação de Marli André na constituição do campo de estudos Formação de professores no Brasil, é inquestionável, mas a continuidade da tarefa aqui iniciada pode trazer elementos de aprofundamento dessa constatação. 


\section{Considerações finais}

Quase chegando ao fim deste diálogo, mesmo incipiente, com Marli André, mediado pelas palavras dos títulos e resumos de seus artigos em periódicos, vai se delineando a conclusão de que essa pesquisadora é uma mulher intelectual do nosso espaço, a Pesquisa Educacional, e do nosso tempo, os últimos 50 anos.

Iniciado com o trabalho do sociólogo Sérgio MICELI, Intelectuais e classes dirigentes no Brasil (MICELI, 1979), os estudos sobre intelectuais tornaram-se uma temática importante também na área de História da Educação no Brasil, tomando como base as propostas de Sirinelli, embora não haja propriamente consenso sobre o que definiria um/uma intelectual.

Magalhães afirma que Há intelectuais na educação, não sendo sinônimas as expressões 'os intelectuais e a educação' ou 'a educação e os intelectuais'. (MAGALHÃES, 2016, p.305)

Senhores da escrita, os intelectuais criticam, idealizam, prescrevem, organizam, avaliam. Há intelectuais fora do quadro de educação-instituição. Torna-se necessário analisar a representatividade de uns e de outros (p. 321).

Xavier (2016) destaca que é possível perceber nos estudos sobre intelectuais:

elementos em comum, como: o conhecimento e poder de síntese sobre a realidade que os caracterizava e que Ihes dava notoriedade; uma unidade nas causas que defendiam, mesmo considerando os diferentes tempos e lugares onde viveram; a consciência sobre o conhecimento produzido e o por produzir; e a defesa da ideia do bem, do belo e do justo. (2016, p.464)

Quer analisando pela representatividade, como propõe Magalhães, quer pela unidade nas causas que defendiam, mesmo considerando os diferentes tempos e lugares onde viveram; a consciência sobre o conhecimento produzido e o por produzir, como enuncia Xavier, Marli André é uma mulher intelectual da educação cujo legado vai além dos seus escritos pois os grupos de pesquisa que criou e dos quais participou, seus alunos e orientandos continuam gerando produção intelectual e formando novos pesquisadores e professores consolidando tal legado.

Reagindo à provocação de Orlando ao dizer que os estudos sobre intelectuais na área de educação se restringem à figura masculina e perguntando: Onde estão as nossas intelectuais da educação? (ORLANDO, 2021, p. 50), encerro esta primeira abordagem dos diálogos com Marli André com a proposta de dar continuidade a este trabalho de analisar a trajetória da produção do conhecimento da mulher intelectual da educação do nosso espaço e do nosso tempo. 


\section{REFERÊNCIAS}

ANDRADE, C. D. de, Poesia e Prosa em um volume. Rio de Janeiro: Editora Nova Aguilar, 1979.

ANDRE, M. E.D.A. A Abordagem Etnográfica: Uma Nova Perspectiva na Avaliação Educacional. In Tecnologia Educacional, Rio de Janeiro, v. 24, p. 9-12, 1978.

ANDRE, M. E.D.A.. Análise de pesquisas sobre Formação de professores: um exercício coletivo. In Psicologia da Educação, São Paulo, v. 10/11, p. 139-153, 2000.

https://revistas.pucsp.br/index.php/psicoeduca/article/view/41405, acessado em 27/09/2021

ANDRE, M. E.D.A.. A Complexa Relação entre Pesquisa e Políticas Públicas no Campo da Formação de Professores. In Educação (PUCRS), Porto Alegre, v. 32 (3), p. 270-276, 2009.

https://revistaseletronicas.pucrs.br/ojs/index.php/faced/article/view/5773 acessado em 27/09/2021

ANDRE, M. E.D.A.. Formação de professores: a constituição de um campo de estudos. In Educação (PUCRS), v.33, p. 06-18, 2010. https://revistaseletronicas.pucrs.br/ojs/index.php/faced/article/view/8075 acessado em $27 / 09 / 2021$

ANDRE, M. E.D.A.. Políticas de apoio aos docentes em estados e municípios brasileiros: dilemas na formação de professores. In Educar em Revista, Curitiba, v. 50, p. 35-49, 2013. https://revistas.ufpr.br/educar/article/ view/34742 acessado em 27/09/2021

ANDRÉ, Marli. Políticas de valorização do trabalho docente no Brasil: algumas questões. In Ensaio (FundaçãoCesgranrio), Rio de Janeiro, v. 23 (86), p. 213-230, 2015. https://revistas.cesgranrio.org.br/index. php/ensaio/article/view/242 acessado em 27/09/2021

ANDRE, M. E.D.A.; ANDERSON, T. . The Development and Evaluation of a Self Questioning Study Tecnique. In Readingresearch Quaterly, Newark/DE-USA, v. 14, n.4, p. 605-623, 1979. https://www.jstor.org/stable/747264 acessado em 27/09/2021

ANDRÉ, M. A jovem pesquisa educacional brasileira (, 2006). In Diálogo Educ., Curitiba, v. 6, n.19, p.11-24, set./dez. 2006. https://periodicos.pucpr.br/dialogoeducacional/article/view/3133 acessado em 27/09/2021

ANDRE, M. E.D.A.; O que dizem as pesquisas nas salas de aula do Primeiro Grau?. In Forum Educacional, Rio de Janeiro, n.4, p. 83-91, 1978.

ANDRE, M. E.D.A.; Um estudo da interação professor aluno na segunda série do primeiro grau. In Cadernos de Pesquisa (Fundação Carlos Chagas), São Paulo: n.28, p. 21-25, 1979.

CERTEAU, M. de. A escrita da história (2a ed.). Rio de Janeiro: Forense Universitária. 2002.

CRUZ, Giseli B.; ANDRE, M. E.D.A. O Ensino de Didática e o aprendizado da docência na visão de professores formadores. In Revista Diálogo Educacional (PUCPR) Curitiba. 12, p. 77-99, 2014. 
HOUAISS, A. Dicionário Houaiss da Língua Portuguesa. Rio de Janeiro: Editora Objetiva Ltda, 2009

LACERDA, CECILIA ROSA ; ANDRE, MARLI ELIZA . Mestrados profissionais em rede: contribuições e desafios para a formação docente. In Revista da FAEEBA- educação e contemporaneidade, Salvador, v. 29, p. 45-60, 2020.

MAGALHÃES, J. Intelectuais e história da educação em Portugal e Brasil. In Cadernos de História da Educação, Uberlândia, v.15, n.1, p. 299-322, jan.-abr. 2016.

MEIRELLES, C. Obra Poética. 2a Ed. Rio de Janeiro: José Aguilar Editora, 1967.

MICELI, S. "Intelectuais e Classes Dirigentes no Brasil (1920-45)", in Inteectuais à Brasileira. São Paulo, Companhia das Letras, pp. 69-291. 1979.

ORLANDO, E. de A.). Mulheres Intelectuais: onde elas estão em nossa História? In Intelectuais e Educação: contribuições teóricas à História da Educação, Evelyn de Almeida Orlando; Peri Mesquida (Orgs.) -- Porto Alegre, RS: Editora Fi, 2021

PESSANHA, E. C. Professor primário: ascensão e queda de uma categoria profissional filiada às camadas médias, Tese de Doutorado. Programa de Pós-graduação em Educação, Universidade de São Paulo. 1992.

PESSANHA, E. C. Marli Elisa Dalmazo Afonso de André: rigor e trabalho coletivo legitimam a pesquisa. In BARRETTO, E. S. DE S. FCC, CONSELHO ; CRUZ, G. B. da ; LUDKE, M. ;. MARLI ANDRE. CADERNOS DE PESQUISA, São Paulo: v. 51, p. 1-21, 2021

SIRINELLI, J. F. Os intelectuais in: RÉMOND, René. Por uma história política. Rio de Janeiro: Ed. UFRJ/Ed. FGV, 1996.

XAVIER, L. N.. Interfaces entre a história da educação e a história social e política dos intelectuais: conceitos, questões e apropriações. In: GOMES, Angela Maria de Castro; HANSEN, Patrícia Santos (Org.). Intelectuais mediadores: práticas culturais e ação política. 1. ed. Rio de janeiro: Civilização Brasileira, 2016.

PESSANHA, E.; Marli André - O legado de uma mulher intelectual do nosso tempo e espaço. Formação Docente Revista Brasileira de Pesquisa sobre Formação de Professores. Belo Horizonte. Vol. 13, nº 28 (p. 67-78) 31 dez. 2021. ISSN: 2176-4360. doi https://doi.org/10.31639/rbpfp.v13i28.548 
